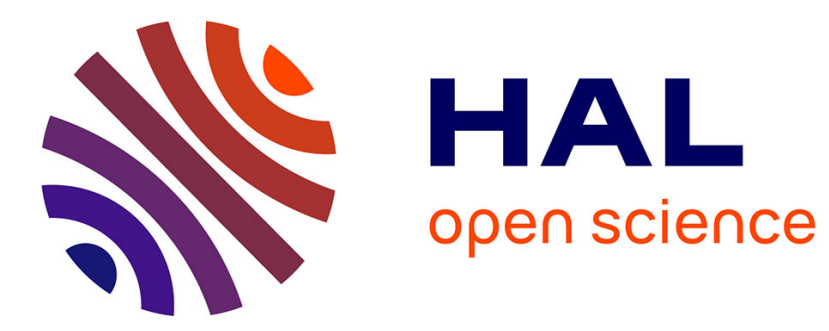

\title{
Particle Tracking Velocimetry for indoor airflow field: A review
}

Sijie Fu, Pascal Henry Biwole, Christian Mathis

\section{To cite this version:}

Sijie Fu, Pascal Henry Biwole, Christian Mathis. Particle Tracking Velocimetry for indoor airflow field: A review. Building and Environment, 2015, pp.34-44. 10.1016/j.buildenv.2015.01.014 . hal01146987

\section{HAL Id: hal-01146987 \\ https://hal.science/hal-01146987}

Submitted on 29 Apr 2015

HAL is a multi-disciplinary open access archive for the deposit and dissemination of scientific research documents, whether they are published or not. The documents may come from teaching and research institutions in France or abroad, or from public or private research centers.
L'archive ouverte pluridisciplinaire HAL, est destinée au dépôt et à la diffusion de documents scientifiques de niveau recherche, publiés ou non, émanant des établissements d'enseignement et de recherche français ou étrangers, des laboratoires publics ou privés. 


\title{
Particle Tracking Velocimetry for indoor airflow field: A review
}

\section{Sijie Fu*, Pascal Henry Biwole, Christian Mathis}

Laboratory of J.A. Dieudonné, Department of mathematics and interactions, CNRS UMR 7351, University of Nice Sophia-Antipolis, 06108 Nice, France.

\begin{abstract}
Airflow field measurement plays a significant role in creating a thermally comfortable indoor environment, by providing adequate quantitative information of indoor air distribution and local air velocity. In recent years, the Particle Tracking Velocimetry (PTV) technique has gradually become a promising and powerful tool for indoor airflow field measurement. This paper firstly gives an overview of the equipments and methods involved in typical PTV applications to indoor environments, and then introduces related applications of PTV for measuring indoor airflow fields. The Particle Streak Velocimetry (PSV) technique for indoor airflow measurement is also introduced. This paper shows how the quantitative and detailed turbulent flow information obtained by PTV measurement is critical for analyzing turbulent properties and developing numerical simulations. The limitations and future developments of PTV and PSV techniques are also discussed.
\end{abstract}

Key words: Particle Tracking Velocimetry (PTV), indoor airflow, measurement, Particle Streak Velocimetry (PSV)

\section{Introduction}

Ventilation and air distribution systems, as a main part of Heating, Ventilation and

*Corresponding author. Tel: +334920762 50; fax: +33493517974

E-mail address: fusijie@unice.fr 
Air Conditioning (HVAC) systems in modern buildings, have received increased attention in recent years [1-10]. The performance of ventilation and air distribution systems not only influences the indoor air quality directly [11, 12], but also strongly affects the total energy consumptions in buildings [13]. Among the evaluations indices referring to ventilation and air distribution systems, there are airflow patterns (such as trajectory, impingement, separation, circulation, reattachment, buoyancy, vortices etc) and airflow field (temperature, velocity and pressure). Numerical simulation using Computational Fluid Dynamics (CFD) models is the most prevalent research method now, and it accounts for about $70 \%$ of studies dealing with the performance of ventilation and air distribution system in buildings [14]. Yet, it is still not possible to predict the structure of indoor airflows with the distinct characteristics of low speed turbulence and three-dimensionality accurately using current computer technology [15]. Therefore, experimental measurements are still a fundamental and important step in the indoor airflow studies, and high quality experimental data plays a key role in the validation and development of numerical models. Besides, the local airflow fields around devices in ventilated rooms, such as heat sources, are still poorly known [16] and experimental data is one of the best ways to understand them.

Because the indoor airflow is usually large-scale, three dimensional, turbulent and unsteady, it is not an easy task to measure it accurately. The most common modern measurement methods for indoor airflow have been summarized by Sun and Zhang [17]. Generally, the measurement methods are categorized into "point-wise" and "globe-wise". The point-wise techniques usually refer to measurement methods that gather only one-point velocity information, such as hot-wire/hot-film/hot-sphere anemometry, which also intrusively disturbs the local airflow, ultrasonic anemometry (UA), and laser Doppler anemometry (LDA). Therefore, they are not the best choice for indoor airflow measurement. Globe-wise techniques usually refer to optical velocimetry and are regarded as an effective alternative tool for measuring indoor airflow distributions. Optical velocimetry can obtain the velocities and related statistical information in a globe domain without disturbing the airflows. Particle Image Velocimetry (PIV), Particle Streak Velocimetry (PSV) and Particle Tracking 
Velocimetry (PTV) are the most prevalent methods among the globe-wise techniques. They have been applied for indoor airflow measurement more and more in recent years.

The PIV is regarded as the most widely used optical velocimetry method for indoor airflow measurement with well-developed technologies, rich experimental literature and available commercial systems. Cao et al. summarized and discussed the PIV technologies and applications for indoor airflow measurement during the past decade [18]. However, typical PIV can only yield two-dimensional vector fields instead of three-dimensional, despite its high spatial and temporal resolution. PSV and PTV are both capable of obtaining velocity vector and air trajectories from one dimension to three dimensions and allow a direct observation of the airflow.

The PTV is a powerful tool to study both indoor air quality and thermal comfort, since the neutrally buoyant tracers used show the displacement of airborne pollutants, and air velocity vectors are measured. This study aims to provide a review of the PTV for indoor airflow measurement, its key components and related research applications. This paper only reviews published PTV methods used by researchers for indoor air applications. The information on hardware, algorithms and results for PTV in liquids, though instructive and sometimes similar, is not considered by this paper. The use of the PSV technique for indoor airflow study is also reviewed. Last, the advantages, limitations and future application of PTV and PSV techniques for indoor airflow measurement are discussed.

\section{PTV equipments and methods for indoor applications}

The term "Particle Tracking Velocimetry" (PTV) was first introduced in the literature in 1980[19]. During the past 30 years, the PTV technique has been widely applied to investigate small-scale flows [20-25], but now it is also gradually being used for the measurement of large-scale flows, especially in indoor airflow studies. The measurement principle and major developments of PTV have been reviewed in previous excellent scientific literatures [26-28], thus we will only present the PTV technologies focusing on the application in large-scale indoor airflows. 
Regarded as a Lagrangian measurement method, PTV determines particle trajectories and velocities through capturing and analyzing each particle image to locate the particles' centers and connecting image tracks. Similar to a PIV system, a PTV system generally consists of four main parts: illumination system, image recording devices, tracer particles and image evaluation methods (algorithms). Fig.1 illustrates a basic 3D-PTV system for large-scale measurement. There is still no available commercial PTV system for indoor airflow measurement. Several representative PTV systems for indoor airflow measurements as well as their applications will be summarized in the following sections.

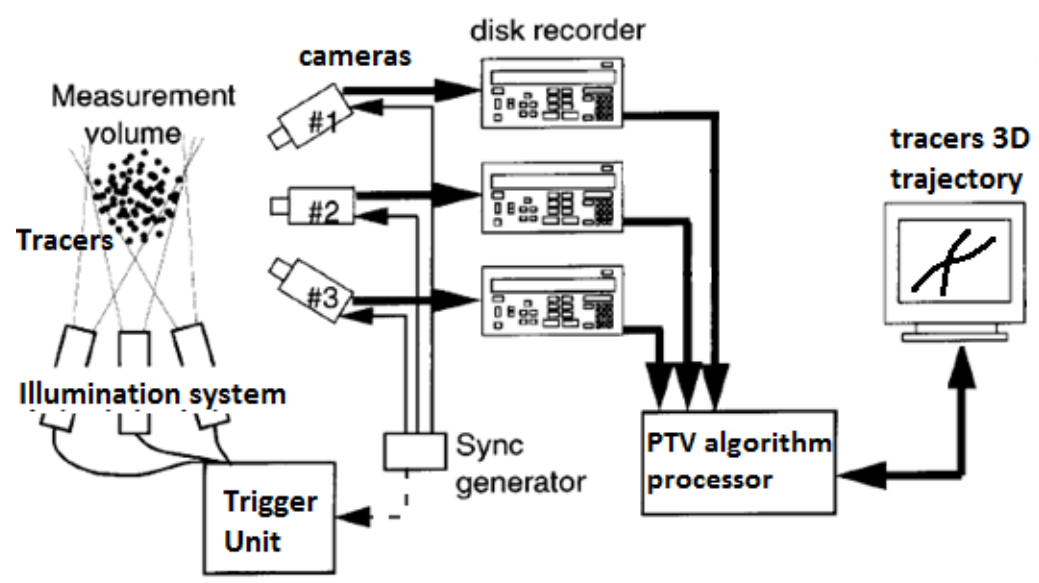

Fig.1. Basic layout of 3D PTV for large-scale measurement

\subsection{Illumination system}

In indoor airflow measurements using the PIV technique, a double-pulsed Nd:Yag laser system with an articulated delivery arm to generate a green light sheet of $532 \mathrm{~nm}$ wavelength is the most widely used illumination system. The laser is also the most universal light source in traditional small-scale PTV measurements [20, 29-32]. However, this light source is unpractical in large-scale measurement volumes with PTV technique, because the low energy of the laser hardly satisfies the illumination needs. Jones et al. estimated that a 10W laser could only illuminate an area of the order of $1 \mathrm{~m}^{2}$ [33]. Thus if the laser is used as the light source in a large-scale measurement volume, 
the power of the laser needs to be huge. It is almost impossible to handle such a laser in ordinary laboratories. Besides, when the thickness of the laser beam expands, the energy density of the laser will also decrease rapidly.

For these reasons, it is more practical to adopt conventional light sources when using the PTV technique for measurements in large volumes. The most generally adopted conventional light sources can be divided into two categories, one that generates light pulses, such as photographic flash lamps, and the other that uses steady state illuminations, such as halogen lamps and arc lamps. For example, a Balcar Quadlite halogen is shown in Fig.2. These light sources have been applied in the PTV systems for indoor airflow measurement to ensure taking a good quality of image [34-38]. The main drawback in using photographic lamps or strobe light is the rapid decrease in light intensity as the frequency increases. Thus, the frequency of the flash is generally limited to 2 or $3 \mathrm{~Hz}$ [38]. This limitation implies that only slow moving flows can be measured. Another limitation is the difficulty to synchronize the flash with the cameras.

It should also be noticed that both pulsed and continuous light sources usually generate a lot of heat so that the indoor airflows may be disturbed. Thus in practice, they are only turned on for a few seconds when the cameras are recording, or they are staged outside the test area behind a glazed panel. In this regard, the use of last generation high power light emitting diodes (LED) could be a promising way to provide light for PTV due to their higher luminous efficacy and their lower heat dissipation compared to traditional illumination devices. LED has been successfully used recently for 3D PTV $[39,40]$.

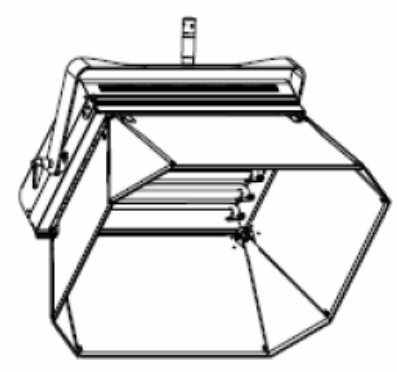

Fig.2. Front view of a Balcar Quadlite halogen lamp used for 3D PTV. [36] 


\subsection{Tracer particles}

Tracer particles affect the quality of indoor PTV measurements directly, since PTV actually measures the velocity and trajectory of flow driven tracer particles instead of the airflow itself. The choice of the tracers is crucial for the reliability of the measurement. That choice is usually a compromise among the considerations of neutral density with respect to the fluid, size and lifetime that suits the phenomenon to be measured, light scattering capability which should be sufficient for image taking.

In this regard, the scattering cross section $C_{s}$ is used to evaluate the scattering behavior of the particles. $C_{s}$ is a function of the ratio of the particle diameter $d_{\lambda}$ to the light wavelength $\lambda$ for spherical particles. Melling compared the approximate $C s$ for particles with different diameters, and found that the larger the particles the stronger the scattering behavior [41].

Tracers of diameter less than $1 \mu \mathrm{m}$ used in small-scale PIV and PTV cannot be used in large-scale PTV since they are too tiny to scatter enough light and to be singled out and tracked individually. Helium-Filled Soap Bubbles (HFSBs) are the most widely used tracer particles in large-scale airflow measurement. The underlying principle is to inflate a liquid film with a lighter-than-air gas to compensate for the weight of the membrane. HFSBs have good characteristics of neutral density, short relaxation time, high light scattering efficiency, relative suitable size ranging from 1 to $4 \mathrm{~mm}$, as well as relative suitable lifetime [42-47]. A picture of a HFSB can be seen on Fig. 3.

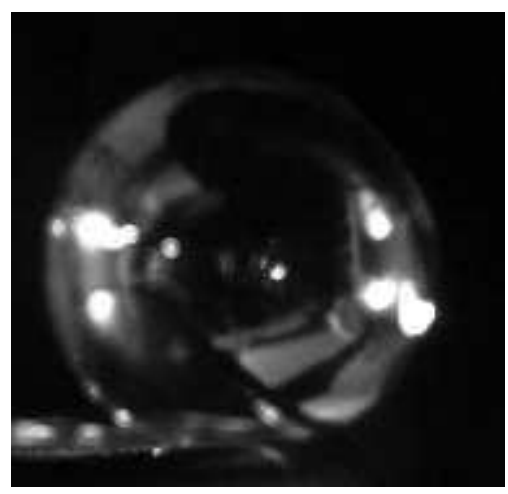

Fig. 3. Single helium filled soap bubble. Light scattered on the shell can be seen. [45] 
A bubble generator nozzle with three concentric tubes is usually used to generate HFSBs, one tube for helium, one for air and the last one for the bubble fluid. The flow rate in each tube is usually controlled separately and determines the bubble's diameter. There are two different types of nozzle used for the generation of bubble fluid [48], one is the Pitot tube type which is the more ancient and still the most used one, and the other is the Orifice type nozzle, which can generate more bubbles per second. A sketch of the orifice type nozzle and a three-channel generator is illustrated in Fig.4. More details regarding the bubble generation can found in Bosbach et al. [47].

(a)

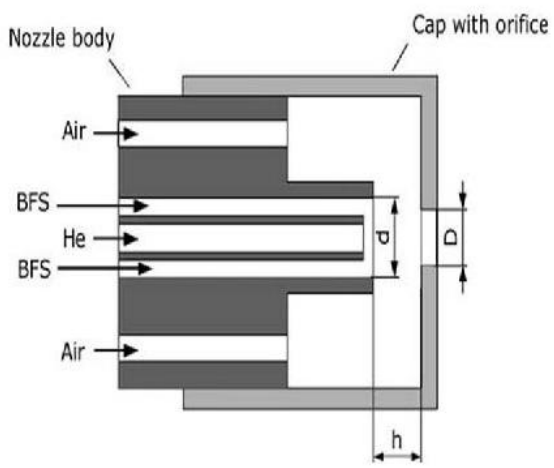

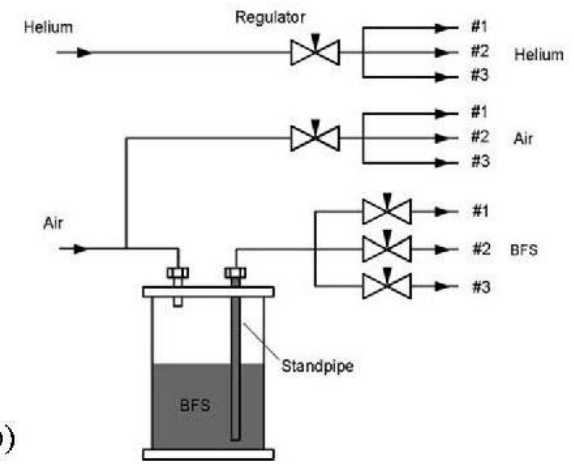

(b)

Fig.4. Sketch used for generation of neutrally buoyant helium filled soap bubbles: (a) the orifice type nozzle; (b) the three-channel generator. [47]

From a theoretical view point, a general equation of motion for a single rigid sphere in the non-uniform flow was given by Maxey and Riley [49]. Based on Maxey and Riley's equation, Kehro and Bragg [50] conducted a complete study of the HFSB physics and showed that a neutral particle reliably follows the flow, provided the changes of properties of the flow are negligible with respect to its diameter. Some experimental and numerical studies were done to compare the effects of different bubble diameters and shell thicknesses on the ratio of fluid density to bubble density. [20, 50] (see Fig. 5). 


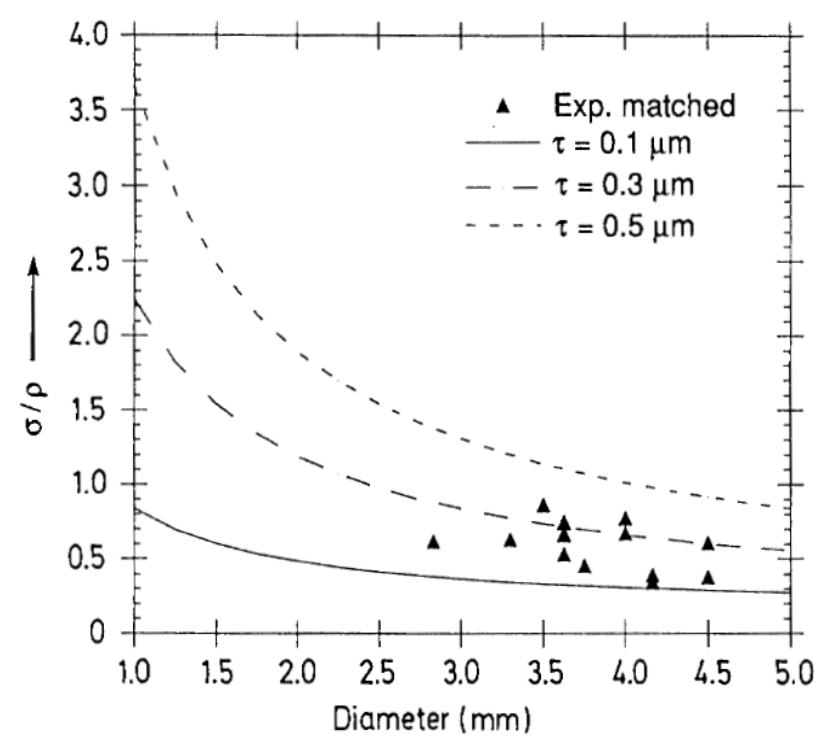

Fig. 5. Influence of bubble diameter and film thickness $\tau$ on density ratio of HFSBs.

In addition, if the external forces (gravitational, centrifugal and electrostatic) can be considered negligible and the particles have approximately spherical shape, an equation satisfying most flows can be found in Melling [41].

When the Reynolds number $(R e)$ is low, Stokes' drag law (Exp.1) is considered to apply to evaluate the tracking behavior of particles [41]. In the equation, where $g$ is the gravitational acceleration, $\rho_{p}$ and $\rho_{f}$ are the density of the particles and the fluid respectively, $\mu$ is the dynamic viscosity of the fluid, and $d_{p}$ is the diameter of the particles. However, it is noticeable that the Stokes' drag law may underestimate the actual velocity lag when the airflow has a high turbulence level.

$$
u_{g}=d_{p}^{2} \frac{\left(\rho_{p}-\rho_{f}\right)}{18 \mu} g
$$

The Stokes number $(S t)$ is also used to evaluate the tracking behavior of particles. $S t$ is the ratio of the particle response time $\tau_{p}$ to the time scale $\tau_{f}$ of the airflow. The Stokes number can be estimated as follows [51]:

$$
S t=\frac{2}{9} \frac{\rho_{p}}{\rho_{f}}\left(\frac{a}{L}\right)^{2} \cdot R_{e}
$$

where $\mathrm{a}$ is the particle radius, $\mathrm{L}$ is the characteristic flow length scale and $\mathrm{Re}$ the 
Reynolds number of the flow. The recommended $S t$ of tracer particles for airflow is less than 0.1[18], which is the case for HFSBs used in slow motion room airflow.

Recently, helium-filled latex balloons (HFLBs) with a diameter of about $150 \mathrm{~mm}$ were used as tracer particles in a large measurement volume to investigate natural convection $[15,38]$. The tracking behavior of the particles was evaluated using Stokes number, and the $S t$ was between 0.02 and 0.2. More detailed analyses of HFLBs can be found in $[15,38]$.

\subsection{Image recording devices}

The maximum frame rate and the camera resolution are the two main factors when choosing image recording devices. The frame rate is chosen based on the maximum airflow velocity so that the particle displacement is less than a quarter of the size of research windows; the rule is as the following equation:

$$
\Delta t \leq \frac{\Delta d_{\max }}{V_{\max }}=\frac{L}{4} / V_{\max }, d_{\max }=\sqrt{d_{x}^{2}+d_{y}^{2}}
$$

where $d_{x}$ and $d_{y}$ are the pixel coordinates of the displacement on the image plane, and $L$ is the pixel size of the research window. Besides, it is helpful to minimize tracking ambiguities by increasing the frame rate as the particle seeding density increases. Therefore, the frame rate should usually be decided so that the maximum displacement of a particle is smaller than the minimum distance between two particles. In practice, frame rates up to $100 \mathrm{fps}$ are usually sufficient to study the indoor airflows away from walls and ventilation inlets.

The size of the particles used, the size of the field visualized, the illumination employed and the background determine the choice of the camera resolution. The general rule is that the particles must be seen clearly. Agui and Jimenez gave the field of observation of a sensor as following [52]:

$$
\text { Field of observation }=\text { Surface of the detector } / M
$$

where $M$ is the enlargement of the optical system. Exp. (5) gives the diameter of a 
particle on the digital image.

$$
d=\left(M^{2} d_{p}^{2}+d_{d}^{2}+d_{r}^{2}\right)^{1 / 2}
$$

where $d_{p}$ is the real diameter of the particle, $d_{r}$ is the size of pixel or grain in the case of a photographic film, and $d_{d}$ is the minimal diameter due to the refraction. $d_{d}$ is given by Adrian as follows [30]:

$$
d_{d}=2.44 \cdot N O \cdot \lambda \cdot(1+M)
$$

where $N O$ is the aperture of the lens and $\lambda$ is the wavelength of the light used. The observable depth of field $\delta_{z}$ where particles are seen accurately is also given by Adrian as follows:

$$
\delta_{z}=4 \cdot N O^{2} \cdot \lambda \cdot\left(1+\frac{1}{M}\right)^{2}
$$

Besides, it is preferable to choose the sensors featuring a high number of gray levels under the condition of poor contrast with the background or very large light sheet. It is noticeable that a large size pixel could offer a better sensitivity but a poorer resolution than a smaller size pixel.

Coupled charged devices (CCD) cameras are the most common image recording devices used in PTV systems for indoor airflow measurement. CCD cameras usually have increased spatial resolution, convenient data transmission and image processing, minimum exposure time, high light sensitivity as well as low background noise. Normally, CCD camera with 8 to 10 bits sensor rate is sufficient for most PTV measurements. More and more complementary metal oxide semiconductor (CMOS) cameras have been employed in PTV systems recently $[16,39]$. Compared to CCD cameras, they allow recording speeds in the range of a few $\mathrm{kHz}$ with acceptable noise levels. A detailed comparison between CCD cameras and CMOS cameras can be found in Hain et al. [53]. Given the small size of the tracers relative to the size of the measuring volumes, most research teams use cameras with pixel resolution equal to or higher than 4 megapixels.

Due to the size of the measuring volumes and the relatively short distance from cameras to the latter, wide-angle lenses from $22 \mathrm{~mm}$ down to $15 \mathrm{~mm}$ are usually used for indoor PTV. Lenses with focal length from $24 \mathrm{~mm}$ to $15 \mathrm{~mm}$ [16] or even less can be 
used. The resulting image distortion is usually compensated for after the camera calibration procedure.

\subsection{Tracking algorithms}

The procedure to obtain particle trajectories from raw particle images can be divided into five main steps: namely multi-camera calibration, image processing, particle center detection, 2D or 3D tracking and 3D reconstruction. A detailed review of usual tracking algorithms can be found in Ouellette et al. [54]. Here, we will focus on the distinct features of PTV algorithms used in large airflow as reported by researchers of this topic.

\subsubsection{Multi-camera calibration}

In a multi-camera system, multi-camera calibration is the way of establishing the mathematical relationship between each camera 2D pixel (image) coordinates and a physical 3D reference frame. The calibration step gives access to the cameras' intrinsic and extrinsic parameters including focal length, principal point, skew angle, distortion coefficients and rotation and translation matrices from each camera reference frame to the physical 3D reference frame. Those parameters are yielded by the minimization of the reprojection error between the known 3D coordinates of the calibration target, and the same coordinates calculated via a mathematical camera model. The calibration algorithms employed do not differ from those used in small scale and liquid PTV. In large scale airflows, Biwole et al. [16] and Barker [55] used the calibration method proposed by Zhang [56] while Li [57] used the procedure presented by Svoboda et al. [58].

The calibration target must be big enough to allow the detection of its specific points by the cameras. The target may be a full three-dimensional object such as a cube, or a two-dimensional (planar) object such as described in Zhang [82]. In the letter case, the target must be moved so that it is viewed from different angles by each 
camera and the in-depth coordinate is derived from the in-place coordinates by trihedral projection as shown on Fig.6 (a). Biwole and Yan et al. [16, 37] used a planar checkerboard with black and white $3 \mathrm{~cm}$ large squares for calibration in a $3.1 \mathrm{~m} \mathrm{x} 3.1$ $\mathrm{m} \times 2.5 \mathrm{~m}$ test-room. The checkerboard had 14 horizontal squares and 10 vertical squares, as shown on Fig.6 (a). A planar checkerboard composed of a 12 x 12 array of $6 \mathrm{~cm}$ black and white squares was also used by Biwole et al. in a mock-up aircraft cabin [36]. Resagk et al. [59] used a large number of coded targets on the walls of a test facility with $4.2 \mathrm{~m}$ length, $3.0 \mathrm{~m}$ width and $3.6 \mathrm{~m}$ height, as shown on Fig. 6(b). Barker [40] used a planar calibration board containing 44 black circles as shown on Fig.6(c). This pattern board seemed to give better calibration results with lower re-projection errors than the checkerboard pattern. Multi-camera calibration may be done before or after particle image acquisition.

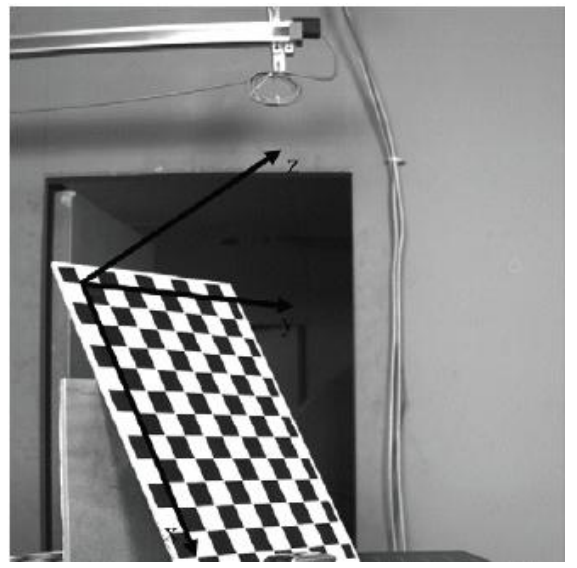

(a) Calibration target used by Biwole et al.[16]

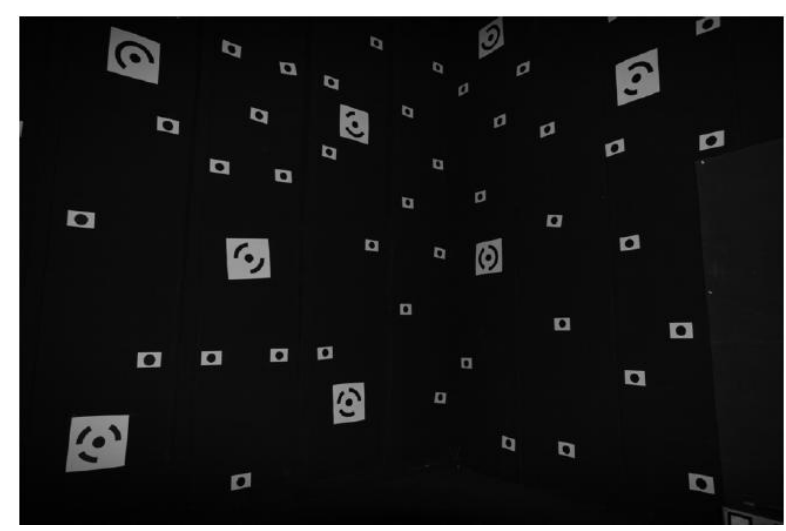

(b) Calibration targets used by Resagk et al.[59] 


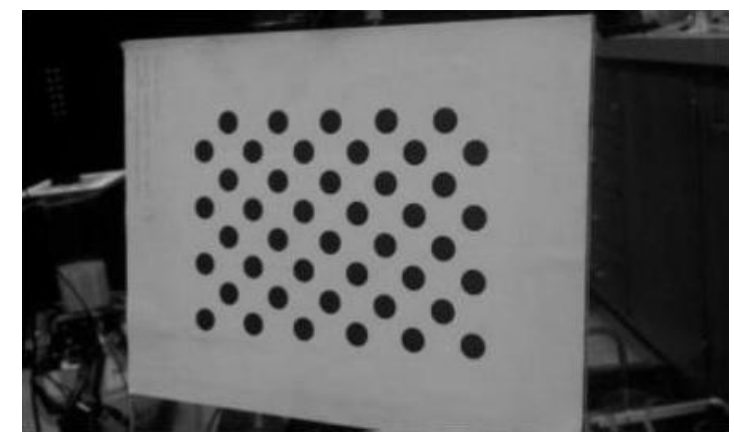

(c) Calibration target used by Barker[40]

Fig.6. Several calibration targets for large scale airflow measurement

\subsubsection{Image processing}

As in other traditional imaging techniques, the background is first averaged then removed from the seeded flow images. The image processing procedure highly depends on contrast between the illuminated particles and the background. In case of poor contrast of the background to the particle images, a high pass filter may be applied by the use of a threshold value setting to zero all pixel values lower than the threshold. Erosion by structuring elements of the form $[1,1]$ and $[1,1]^{\mathrm{T}}$ can also be used to get rid of single-pixel noise.

A particularity of 3D PTV in large scale flows arises when helium filled bubbles get close to the recording cameras. Those bubbles can create many fake particle centers, which are out of the common view field and therefore must be removed. To do so, Biwole et al. [16] proposed an image processing procedure consisting of filling the particle by the use of structuring element before subtracting them from the original particle images.

\subsubsection{Particle center detection}

For particle center detection, the weighted averaging method [27, 60], is the most used with gas filled bubbles [16, 40,42] because of its easy implementation and effectiveness. In spite of higher capabilities when handling overlapping particles, 
Gaussian fitting methods [61, 62] perform poorly on gas filled soap bubbles because their light intensity profile cannot always be approximated by a Gaussian function. One particle can feature two distinct peaks of intensity as shown on Fig. 3. Besides, Gaussian fitting methods are computationally expensive.

\subsubsection{Particle tracking}

There is no difference tracking schemes used for PTV in liquids and PTV in the air. The tracking strategies may be divided into two types: The first type (Fig.7 (a)) consists in first tracking each particle in the image domain of each camera separately though time based on the successive frames (2D tracking), and then reconstructing the $3 \mathrm{D}$ trajectories by spatial matching of the 2D trajectories obtained. The second type (Fig.7 (b)) is the inverse: Here, the particles 3D coordinates are calculated at each time step and the tracking is done directly in the object domain.

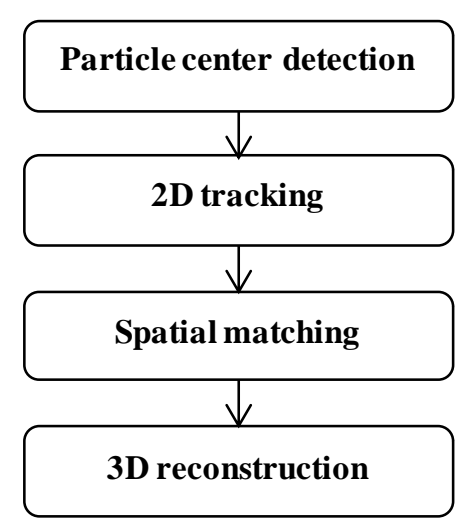

(a)

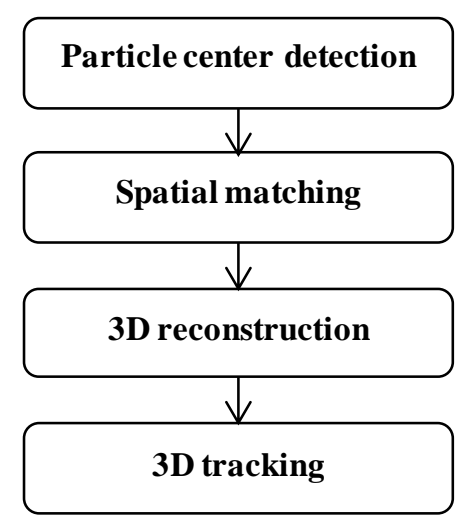

(b)

Fig.7. Flow chart of particle tracking strategies

The main advantage of the first type of tracking is its easy implementation since the actual tracking is done separately on each camera. However, this method is less accurate than the second for complex flow trajectories. For example, spiral trajectories may be judged unphysical in the $2 \mathrm{D}$ image domain while they are realistic in the $3 \mathrm{D}$ domain. The main drawback of the second type of algorithms is the accumulation of 
computational errors with time since the $3 \mathrm{D}$ reconstruction must be done at each time step.

Some hybrid tracking scheme using features from each type can be found in the literature [31]. For the study of indoor air, Zhao et al. [63], Sun et al. [34,35], Yan et al. $[37,64]$ and Biwole et al. $[16,36]$ used the first type of scheme while Lobutova et al. $[15$, $38]$ and recently Barker et al. [40, 65] and Klimentew et al. [66, 67] used the second type of scheme with good results. To track particle from one time step to the next, all teams have used multi-frame tracking algorithms [28, 31] due to their capacity of tracking trajectories for a long period and their robustness against noise. Those algorithms consist in extrapolating the $2 \mathrm{D}$ or $3 \mathrm{D}$ position of the particle on the next frame based on three to five previous positions. The extrapolated position is used as a cost function that has to be minimized among different candidate particles inside a search region. Depending on the heuristic, the cost function accounts for constraints on the amplitude and direction of velocity or acceleration of the particle.

In addition, many other algorithms have been developed in the past, such as PIV-PTV tracking, probability-match tracking as well as velocity gradient-tensor tracking [68-70]. Most of these algorithms use extrapolation methods to predict the future particle centers. Although they perform well in the condition when the particle positions are detected precisely, their performance drops significantly with the increase of input noise [54]. Li et al. developed a novel multi-frame tracking algorithm by employing a regression method instead of the extrapolation method to process the noisy data. Their regression method used up to five previous particle positions to create trajectories [71]. Biwole et al. proposed a method combining traditional PIV fast-normalized cross-correlation to account for particle shape and light intensity, and Lagrangian extrapolation based on up to three previous positions to account for particle history [36].

For 3D reconstruction, the epipolar constraint has become a standard and well known method [27]. Biwole [36] proposed another method based on the comparison of particles 3D coordinates calculated by two cameras at a time in a three-camera system. His method allowed avoiding the explicit calculation of the fundamental matrix used in 
the epipolar constraint method and permitted spatial correspondence of particle from the first frame. Yan developed a hybrid spatial matching strategy which improved the detecting rate and increased detectable volumes [37].

\subsubsection{Tracking accuracy assessment methods}

Apart from errors due to particle weight neutrality, errors in 3D PTV mainly come from the error in the determination of calibration parameters and errors in the tracking algorithms internal design. The following methods have been used to evaluate the tracking accuracy of PTV methods for indoor air:

- The distance between a known trajectory and the reconstructed trajectory: Lobutova [38] gave a precise trajectory to a single glass sphere by the use of a stepper motor with a preset angular velocity. Biwole [36] used a single table tennis ball which he manually displaced on eleven precisely known locations. Barker [40] used a static object with fixed particles $3.0 \mathrm{~mm}$ in diameter.

- The use of direct comparison between raw and calculated trajectories by back projection: this method consists of projecting the calculated 3D trajectories onto the cameras image planes according to their calibration. The resulting $2 \mathrm{D}$ trajectories are then compared to the actual raw particle $2 \mathrm{D}$ trajectories obtained by simply adding up all particle image frames. This method allows avoiding the use of a specially designed validation apparatus. The result of such a comparison can be found in Biwole et al. [16].

- The use of synthetic particles: instead of real particles, images of synthetic particles with known 3D displacements are created based on the forward projection of their successive 3D coordinates onto each camera image plane using real camera calibration data. The calculated and synthetic trajectories are then compared.

- The use of PIV 3D standard image data sets: Particle images and their true trajectory are given in standard image data files, such as those released by the Visualization Society of Japan [55]. Since the calibration details are also given, users can test the effectiveness of their PTV algorithms. 
The assessment parameters used are the distance between actual and calculated trajectory [38], the ratio of the number of correct 3D trajectory tracking by the total number of input 3D trajectories $[28,54]$, the number of 3D tracked positions which are identical to input 3D particle positions [71], and the relative difference between the known magnitude of acceleration and the measured value [40]. The value of those parameters greatly depends on the seeding density and the complexity of the measured flow but for correctly tracked particles, the error between the reconstructed and real path is generally less than the particle diameter i.e. a few millimeters $[16$, 38].This is consistent with the fact that the method is based on tracking each individual particle image. A methodology to specifically assess the accuracy of PTV for near wall measurements based on synthetic particles can be found in Kähler et al. [72].

\section{Applications of PTV in indoor airflow field measurements}

The applications of PTV technique for indoor airflow measurements are summarized in this section. Tab. 1 lists the representative systems as well as their related applications reviewed mainly from the available international publications. This review may not be complete due to the continuous developments of PTV technique, but represent the status and trend of indoor PTV applications now.

The measurement of airflow patterns and velocities in ventilated rooms is the main application. Three research groups are well known in the field. The bio-environmental engineering (BEE) research group of the University of Illinois at Urbana-Champaign developed both a large-scale Volumetric PTV (VPTV) system [34, 35] and a large-scale Hybrid PTV (HPTV) system [37] and employed them to investigate global and local airflow issues. They obtained abundant experimental data for validating and developing CFD models [35, 37, 63, 64, 73-75]. Fig.8 shows an example of their measurement results using the HPTV system. Their studies suggested the PTV technique could be a practical method to help predicting indoor air distribution in large-scale spaces. 


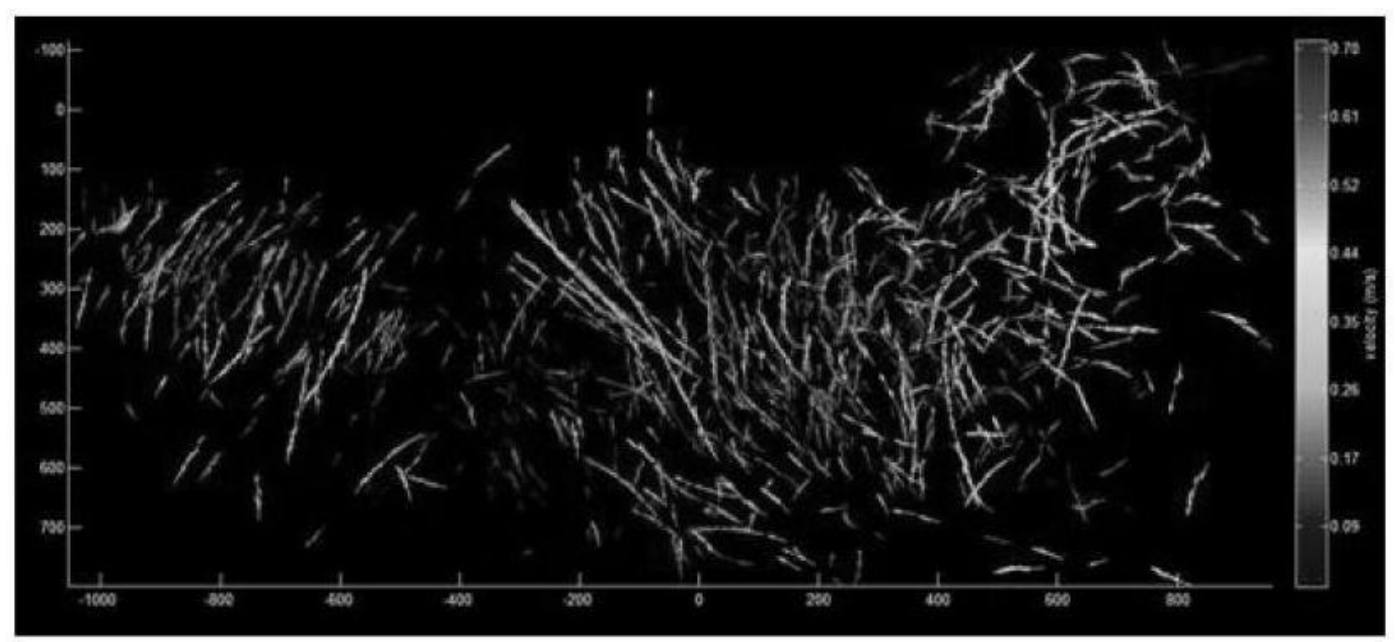

Fig.8. Measurement of global airflow field at a spliced plane with $100 \%$ ventilation rate by Yan,

BEE group [37]

Research groups at Germany's Universities of Technology of Ilmenau, Dresden, Berlin and Aachen developed and applied a 3D PTV system to investigate convection. Lobutova et al. [15, 38] studied large-scale flow patterns in Rayleigh-Bénard convection. Their results confirmed that four different flow patterns existed in the bulk region. Probability density functions of the velocity and acceleration fluctuations were calculated from the measured data. The sketch of the experimental facility used and the 3D trajectories obtained are illustrated in Fig.9. Steinhoff et al. employed their redesigned 3D-PTV system to measure the structure of natural convection airflow and mixed natural and forced convection airflow [76]. Their studies also suggested 3D-PTV technique could be a powerful measurement tool for 3D and time-dependent analysis of indoor airflows.

The Research group at the Thermal Sciences Research Center of the University of Lyon built a PTV system to help validation and improvement of CFD models of air distribution in rooms. They mainly studied forced convection and natural convection over heat sources. Fig. 10 shows the path of helium filled soap bubbles over a heater in a room [16]. 


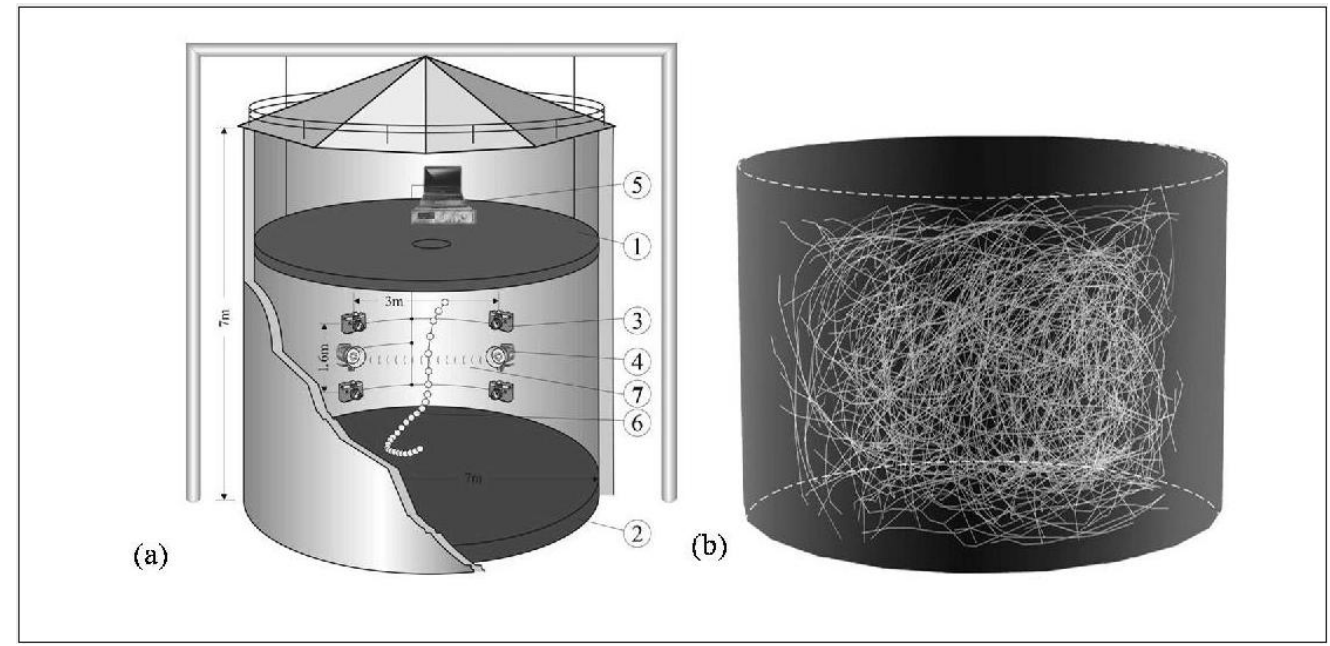

Fig.9. PTV measurement for natural convection using HFLBs: (a) Experimental facility; (b) 3D balloon trajectories. [38]

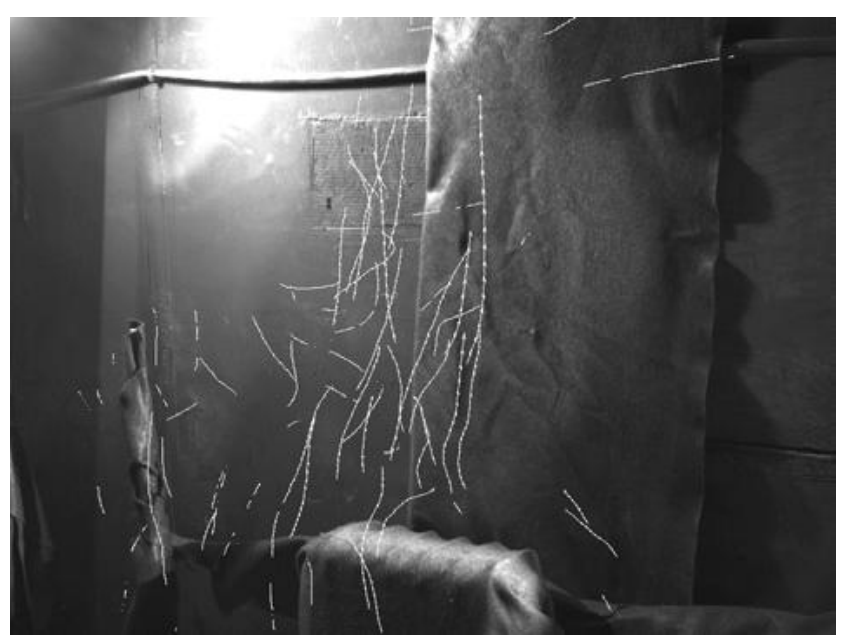

Fig.10. PTV measurement over a heater in a room [16] 
Tab.1 Summary of PTV applications for indoor airflows

\begin{tabular}{|c|c|c|c|c|c|c|}
\hline Researchers & Affiliation & Illumination system & $\begin{array}{l}\text { Image recording } \\
\text { device }\end{array}$ & Tracer particles & $\begin{array}{l}\text { Measurement scale } \\
(\mathrm{L} x \mathrm{~W} \times \mathrm{H})\end{array}$ & Application \\
\hline \multirow[b]{2}{*}{ Resagk et al. } & & & Four Canon EOS & \multirow{4}{*}{ HFSBs, $3 \mathrm{~mm}$} & \multirow{4}{*}{$4.2 \mathrm{~m} \times 3.0 \mathrm{~m} \times 3.6 \mathrm{~m}$} & \\
\hline & $\begin{array}{l}\text { TU Ilmenau \& } \\
\text { TU Berlin \& }\end{array}$ & Halogen lamps & $\begin{array}{l}\text { 20D CMOS cameras } \\
\text { (resolution:3504 x }\end{array}$ & & & $\begin{array}{l}\text { Visualization of } \\
\text { large-scale forced }\end{array}$ \\
\hline \multirow{2}{*}[59,77]{} & TU Dresdan & & 2336 pixels, $5 \mathrm{fps}$ & & & airflow structure \\
\hline & & & set） & & & \\
\hline \multirow{5}{*}{ Biwole et al. } & & & Three Dalsa 4M60 & \multirow{9}{*}{ HFSBs, $1.2-3 \mathrm{~mm}$} & \multirow{7}{*}{$3.1 \mathrm{~m} \times 3.1 \mathrm{~m} \times 2.5 \mathrm{~m}$} & \\
\hline & & & CMOS cameras $(4$ & & & \\
\hline & & Six Balcar Quadlite & Megapixels, & & & Measurement of air \\
\hline & Univ. of Lyon \& & halogen lamps (power: & resolution: $2352 \mathrm{x}$ & & & velocity \\
\hline & Univ. of Illinois at & 1000W each) & 1728 pixels, $15 \mathrm{~mm}$ & & & distributions under \\
\hline \multirow{4}{*}[16,36]{} & Urbana-Champaign & & Canon lens for each & & & different measured \\
\hline & & & camera, 100 fps set) & & & conditions \\
\hline & & Six spotlights (power: & Three TMC-1402 & & \multirow{2}{*}{$5.5 \mathrm{~m} \times 3.7 \mathrm{~m} \times 2.4 \mathrm{~m}$} & \\
\hline & & 500W each) & CL CCD cameras & & & \\
\hline
\end{tabular}




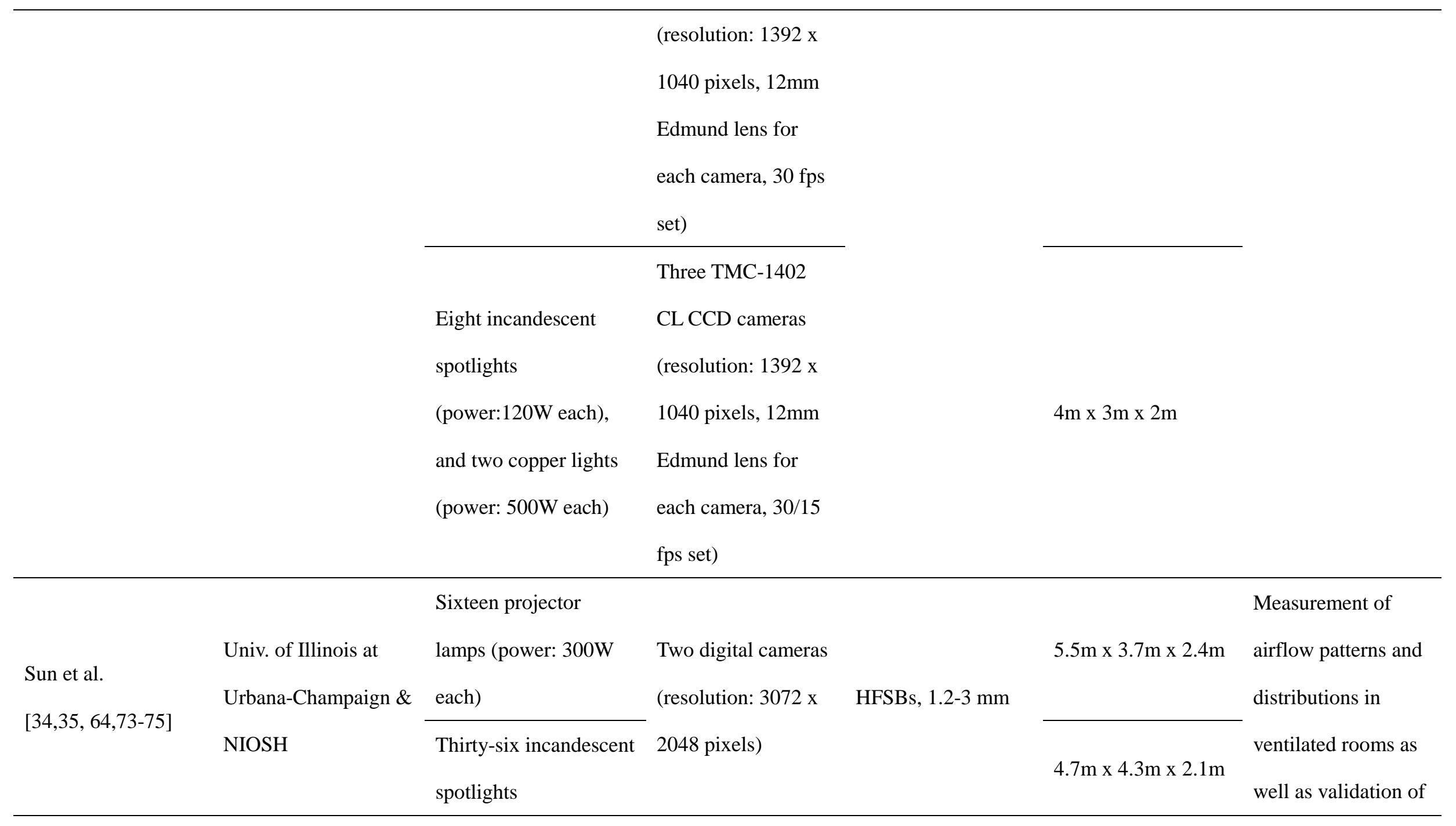




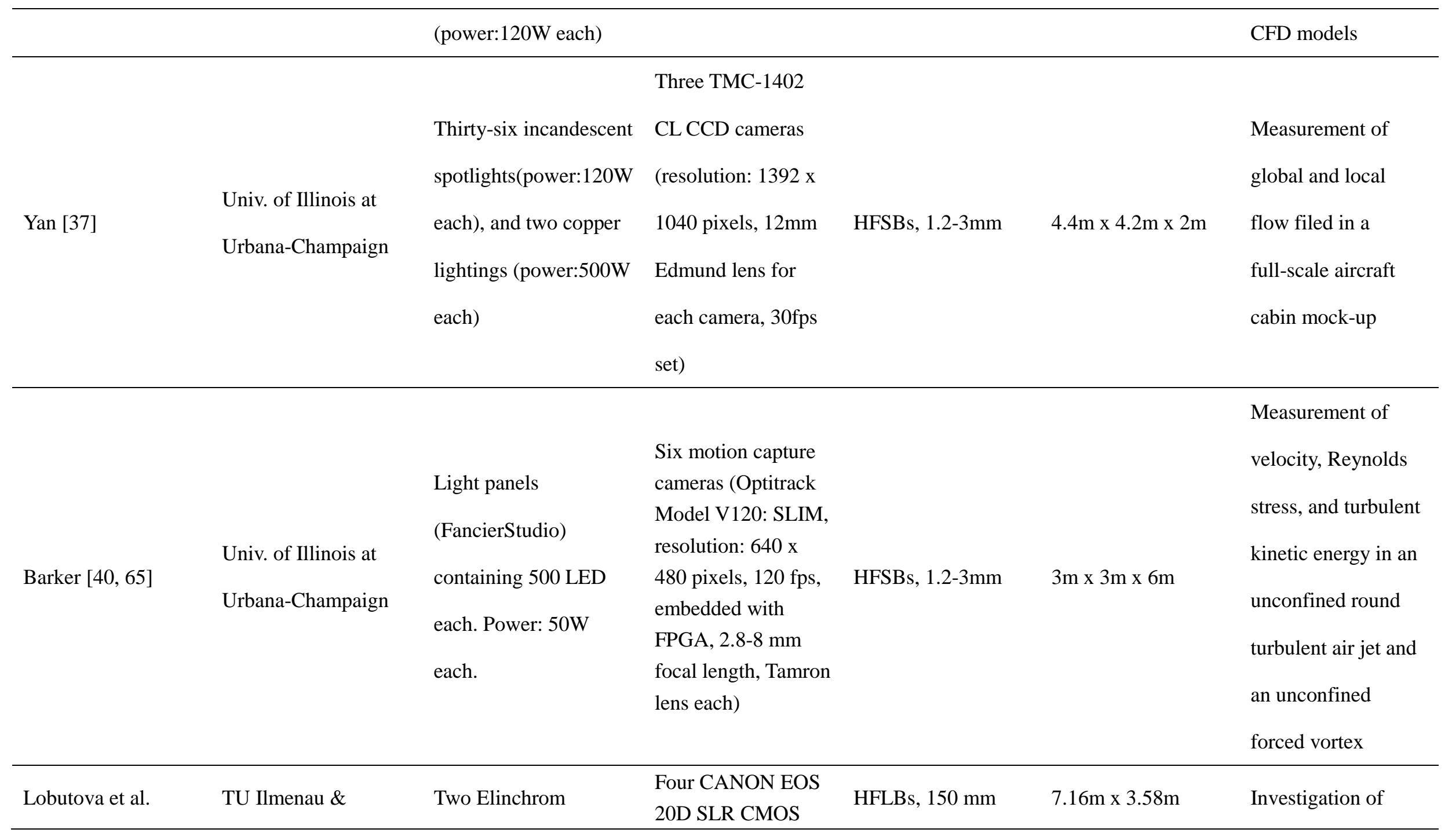




\begin{tabular}{|c|c|c|c|c|c|c|}
\hline$[15,38]$ & $\begin{array}{l}\text { RWTH Aachen Univ. } \\
\text { \& Audi Co. }\end{array}$ & $\begin{array}{l}\text { high-power flash } \\
\text { lamps, } 3 \mathrm{~Hz}\end{array}$ & $\begin{array}{l}\text { cameras (8 } \\
\text { megapixels, } \\
\text { CANON } \\
\text { EFS } 10-22 \\
\text { mmf/3.5-4.5 USM } \\
\text { lenses, } 3 \mathrm{fps} \text { ) }\end{array}$ & & (D x H, cylinder) & $\begin{array}{l}\text { large-scale natural } \\
\text { convection airflow }\end{array}$ \\
\hline $\begin{array}{l}\text { Steinhoff et al. } \\
{[39,76]}\end{array}$ & $\begin{array}{l}\text { RWTH Aachen Univ. } \\
\& \text { TU Ilmenau }\end{array}$ & $\begin{array}{l}\text { source (power: } 1500 \\
\text { lpm each) }\end{array}$ & $\begin{array}{l}\text { Distagon } \\
\text { 25MM/F2,8 ZF2 } \\
\text { f-mount lens, } 25 \\
\text { fps) }\end{array}$ & HFSBs, 2mm & $5 \mathrm{~m} \times 4 \mathrm{~m} \times 3 \mathrm{~m}$ & $\begin{array}{l}\text { and mixed(natural } \\
\text { and forced) } \\
\text { convection airflow }\end{array}$ \\
\hline
\end{tabular}

Tab.2 Brief summary of PSV systems for indoor airflows

\begin{tabular}{|c|c|c|c|c|c|}
\hline Researchers & Affiliation & Illumination system & Image recording device & Tracer particles & Measurement scale \\
\hline Scholzen and Moser [78] & ETH-Zürich & $\begin{array}{l}\text { 120mm white light sheet } \\
\text { (several air-cooled } \\
\text { 400W arc lamps) }\end{array}$ & $\begin{array}{l}\text { Three synchronous } \\
\text { photographic cameras }\end{array}$ & HFSBs & $2.4 \mathrm{~m} \times 1.7 \mathrm{~m} \times 1.2 \mathrm{~m}$ \\
\hline
\end{tabular}




\begin{tabular}{|c|c|c|c|c|c|}
\hline Machacek [45] & ETH-Zürich & $\begin{array}{l}\text { Halogene spot lamps } \\
\text { (power: } 2000 \mathrm{~W}, 1000 \mathrm{~W} \text {, } \\
\text { 120W) }\end{array}$ & $\begin{array}{l}\text { Two Pulnix TM6710 } \\
\text { CCD cameras } \\
\text { (resolution: } 640 \text { x } 480 \\
\text { pixels, 8mm Schneider } \\
\text { Kreuznach lens,120fps) }\end{array}$ & HFSBs & $4 m \times 3 m \times 2 m$ \\
\hline $\begin{array}{l}\text { Rosenstiel and Grigat } \\
\text { [81] }\end{array}$ & TU Hamburg-Harburg & A gas-discharge lamp & Pulnix TM-1010 camera & HFSBs & Covering $4 \mathrm{~m}^{2}$ \\
\hline
\end{tabular}




\section{PSV technologies and applications for indoor airflow}

The principle of the PSV technique is the capture of particle streak images by using a longer camera exposure time than for the PTV method. The set-up of a 2D PSV system is the same as a typical PIV system. The performance of PSV measurements for two-dimensional flow fields is excellent, but they perform poorly in three-dimensional fields when a narrow laser sheet is used in the systems because the streaks may be truncated [30]. Therefore, thick light sheet have been tested for three-dimensional airflow measurements in large volumes.

A brief summary of 3D-PSV measurement for indoor airflow is listed in Tab.2. Scholzen and Moser developed a 3D PSV system with a 120mm thick white light sheet, and tracked particles in a $2.4 \mathrm{~m} \times 1.7 \mathrm{~m} \times 1.2 \mathrm{~m}$ ventilated space. Although good results were obtained, the depth of the tracked field was limited to $12 \mathrm{~cm}$ [78]. Machacek reported a 3D large-scale PSV system for wind tunnels. Halogen spot lamps were applied in the system, and three velocity components could be measured in a volume of about $1.5 \mathrm{~m}^{3}$ large. However, the spatial resolution was insufficient due to the low particle seeding density affected by the crossing of particle path segments [42]. Sun and Zhang employed a PSV system with a special designed algorithm to measure the airflow field in a $5.5 \mathrm{~m} \times 2.4 \mathrm{~m} \times 3.7 \mathrm{~m}$ test room. Although their method gave acceptable results, the depth of the tracked area was only $6.5 \mathrm{~cm}$ and many particle streaks were bowed [79]. Rosenstiel and Grigat developed a new segmentation method for large-scale PSV systems. Local image statics combined with classic edge detection and removal of the scene background was considered, thus allowing a good noise removal system. An algorithm for solving the classification problem of binarized stark segments was also proposed, and a comparison to previous existing PSV systems [80] showed better results [81]. The extracted vector fields from recorded streak images in a full-scale aircraft cabin mock-up are illustrated in Fig.11. Recently, some researchers have used the PSV technique to study the air motion around the human body and its interactions with the room ventilation [82]. They found that convective heat transfer coefficients around the body strongly increase with falling room temperature, while 
radiative heat transfer coefficients decrease.

(a)

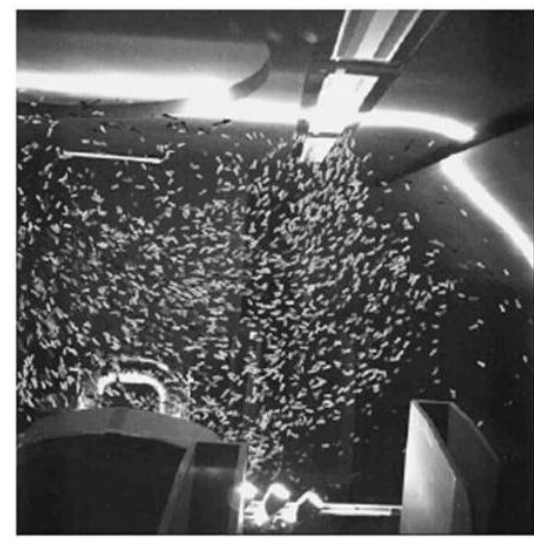

(b)

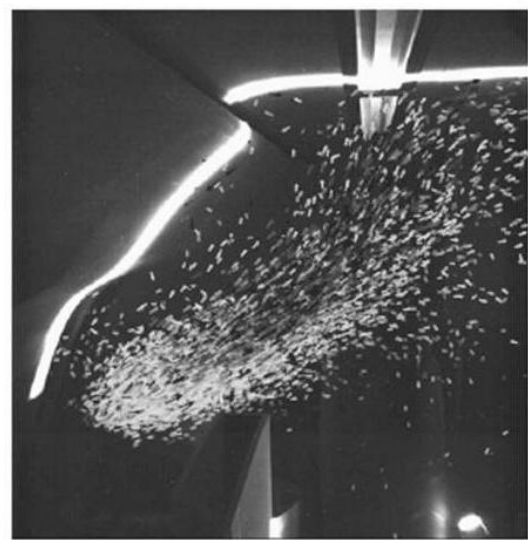

Fig.11. Velocity field extracted recorded in a full-scale aircraft cabin mock-up: (a) from 2525 streaks; (b) from 4476 streaks. [81]

\section{Limitations and future developments}

The limitations and needed future developments of PTV and PSV techniques for indoor airflow applications are concerned both with the equipment and the methods.

\subsection{Equipment}

The powerful light sources employed in large scale PTV and PSV applications interact with the flow through convection and radiation heat transfers. As mentioned in section 2.1, the design and generalization of high light power, low heat generation light sources such as LED should help decrease this unwanted effect.

Regarding the tracer particles, the main limitation of HFLBs and HFLBs arises from the fact that the size of tracers should be smaller than the smallest characteristic length of the studied phenomena. Therefore, those tracers cannot be used to study boundary layer flows. It is also difficult to use them in strongly turbulent flows since their size is usually bigger than the Kolmogorov length scales (the smallest scales in the spectrum that form the viscous sub-layer range). Another limitation arises from the 
lifetime and generation rate of tracer particles produced by current commercial generators, which are respectively limited to about two minutes and 300 particles per second [83]. The design of longer lasting particles and higher generation rate generators is critical to track longer air trajectories and to increase the spatial resolution of the measurement. Such a task has already been successfully tackled by some research teams [47].

Regarding recording devices, the development and use of cameras with ever higher pixel resolution along with faster data processing systems to avoid bottlenecks should help detect more particles in the measured flow and increase the seeding densities.

\subsection{Methods}

The PTV technique usually results in complex and time consuming tracking algorithms. The computation of a few tens of images with a few thousand of particles requires several hours on a desktop computer. To solve this problem, real-time 3D PTV is being researched. Among the most promising solutions to reduce the processing time is the parallel-processing framework. Employing these methods, a 100 to 200 -fold speedup has already been reported by various researchers $[65,84,85]$. The authors believe that this excessive data processing time along with the experimental expertise needed for multi-camera calibration are the main causes limiting the development of commercial PTV systems.

The future development of PTV algorithms should also be aimed at increasing the number of particle that can be tracked. Mainly because of overlapping particle image issues, the seeding density is currently limited to around two thousand particles in most indoor air applications. This limitation seriously reduces the spatial resolution of the method.

In order to cope with the large dynamical range in room airflow i.e. when the velocity difference between inlets and the central space is important, hybrid PSV-PTV algorithms have to be developed, with PSV working on high velocity areas and PTV working on low velocity areas. Such hybrid algorithms have already started being 
investigated [37].

Another foreseeable application is the development of multi-PTV systems for larger rooms such as atriums or conference rooms. More than the challenges in terms of multi-camera calibration and time synchronization, the major issue is to individually track thousands of tiny particles from one 3D PTV field to the next one. In this regard, the most obvious tag would be each particle's 3D coordinates.

Last, it is also noticeable that the PTV technique is not always the optimum option for indoor airflow studies. Near the inlets and outlets where the inlet air velocity is high or close to the walls, laser Doppler velocimetry or hot wire velocimetry, are usually better choices to yield turbulence statistics.

\section{Conclusion}

The key technologies composing a typical PTV system for indoor airflow applications were introduced and discussed. It was noted that no universally applicable PTV system has been found, as many assumptions and compromises had to be made in practical applications in order to satisfy the particular research needs. PSV systems for indoor airflow measurement were also briefly reviewed.

The reviewed publications show that the PTV technique has gradually become a powerful tool for indoor airflow measurement, but the range of applications is still very limited, mainly concentrating on full-scale model measurements. Very few studies on sub-scale residence environment were found, showing that there is still a lot to be gained from the use of the technique for indoor airflow study.

The validation and development of CFD numerical models for indoor environment prediction need to be supported by high quality experimental data. Although the PIV technique has been widely adopted to obtain experimental data for validating numerical models [86-89], it usually only measures the airflow velocity fields inside the laser sheet, and therefore, the numerical models cannot be validated for a fully three-dimensional flow. The PTV technique, as a powerful 3D measurement tool, obtains more complete experimental data to validate and develop numerical models 
from a holistic point of view. Further, information on the flow structures and airborne pollutant dispersion characteristics can be extracted directly from the data. The development of user friendly 3D PTV procedures with faster tracking algorithms is a key step toward the emergence of commercial systems.

\section{Acknowledgements}

This work was supported by a funding from the French National Research Agency (ANR) through the FLUBAT project (ANR-12-VBDU-0010). The authors would like

to thank the Agency and all the members of the project for their support. The authors would also like to acknowledge the financial support for this work through the grant "Bourse Doctorale Régionale-Volet DAS" from the Région Provence-Alpes-Côte d'Azur, France.

\section{References}

[1] Niachou. K, Hassid. S, Santamouris. M, Livada. I. Experimental performance investigation of natural, mechanical and hybrid ventilation in urban environment. Build Environ 2008; 43(8): $1373-82$

[2] Chen. Q, Lee. K, Mazumdar. S, Poussou. S, Wang. L, Wang. M, et al. Ventilation performance prediction for buildings: Model assessment. Build Environ 2010; 45(2): 295-303.

[3] Kato. S, Ito. K, Murakami. S. Analysis of visitation frequency through particle tracking method based on LES and model experiment. Indoor Air 2003; 13(2):182-93.

[4] Zhai. Z, Johnson. M-H, Krarti. Assessment of natural and hybrid ventilation models in whole-building energy simulations. Energ Buildings 2011; 43(9): 2251-61.

[5] Schulze. T, Eicker. U. Controlled natural ventilation for energy efficient buildings. Energ Buildings 2013; 56: 221-32.

[6] Homod. R, Sahari. K. S. M. Energy savings by smart utilization of mechanical and natural ventilation for hybrid residential building model in passive climate. Energ Buildings 2013; 60: $310-29$.

[7] Ji. Y, Lomas. K. J, Cook. M. J. Hybrid ventilation for low energy building design in south China. 
Build Environ 2009; 44(11): 2245-55.

[8] Menassa. C. C, Taylor. N, Nelson. J. Optimizing hybrid ventilation in public spaces of complex buildings - A case study of the Wisconsin Institutes for Discovery. Build Environ 2013; 61: 57-68. [9] Lomas. K. J, Cook. M. J, Fiala. D. Low energy architecture for a severe US climate: Design and evaluation of a hybrid ventilation strategy. Energ Buildings 2007; 39(1): 32-44.

[10] Seppänen. O. Ventilation Strategies for Good Indoor Air Quality and Energy Efficiency. Int J Vent 2008; 6(4): 297-306.

[11] Li. X, Niu. J, Gao. N. Co-occupant's exposure to exhaled pollutants with two types of personalized ventilation strategies under mixing and displacement ventilation systems. Indoor Air 2013; 23(2): 162-71.

[12] Li. Y, Leng. G. M, Tang. J. W, Yang. X, Chao. C. Y. H, Lin. J. Z, et al. Role of ventilation in airborne transmission of infectious agents in the built environment - a multidisciplinary systematic review. Indoor Air 2007; 17(1): 2-18.

[13] Lim. T. S, Schaefer. L, Kim. J. T, Kim. G. Energy benefit of the underflorr air distribution system for reducing air-conditioning and heating loads in buildings. Indoor Built Environ 2012; 21(1): $62-70$.

[14] Chen. Q. Ventilation performance prediction for buildings: A method overview and recent applications. Build Environ 2009; 44(4): 848-58.

[15] Lobutova. E, Resagk. C, Rank. R, Dirk. Müller. Extended three dimensional particle tracking velocimetry for large enclosures. In: Nitsche. W, Dobriloff. C. Imaging Measurement Methods for Flow Analysis. Berlin: Springer; 2009, p. 113-24.

[16] Biwole. P. H, Yan. W, Zhang. Y, Roux J-J. A complete 3D particle tracking algorithm and its applications to the indoor airflow study. Meas Sci Technol 2009; 20(11): 1154-66.

[17] Sun. Y, Zhang. Y. An overview of room air motion measurement: technology and application. HVAC\&R Res 2007; 13(6): 929-50.

[18] Cao. X, Liu. J, Jiang. N, Chen. Q. Particle image velocimetry measurement of indoor airflow field: A review of the technologies and applications. Energ Buildings 2014; 69: 367-80.

[19] Robben. F, Cheng. R. K, Popovich. M. M, Weinberg. F. J. Associating particle tracking with laser fringe anemometry. J Phys E: Sci Instrum 1980; 13(3): 315-22.

[20] Suzuki. Y, Kasagi.N. Turbulent air-flow measurement with the aid of 3-D Particle Tracking 
Velocimetry in a curved square bend. Flow Turbul Combust 1999; 63 (1-4): 415-22.

[21] Lee. S. J, Kim. S. Simultaneous measurement of size and velocity of microbubbles moving in an opaque tube using an X-ray particle tracking velocimetry technique. Exp Fluids 2005; 39 (3): 492-7.

[22] Virant. M, Dracos. T. 3D PTV and its application on Lagrangian motion. Meas Sci Technol 1997; 8 (12): 1539-52.

[23] Holzner. M, Liberzon. A, Nikitin. N, Lüthi. B, Kinzelbach. W, Tsinober. A. A Lagrangian investigation of the small-scale features of turbulent entrainment through particle tracking and direct numerical simulation. J Fluid Mech 2008; 598: 465-75.

[24] Kim. S, Lee. S. J. Measurement of Dean flow in a curved micro-tube using micro digital holographic particle tracking velocimetry. Exp Fluids 2009; 46 (2): 255-64.

[25] Satake. S, Kunugi. T, Sato. K, Ito. T, Kanamori. H, Taniguchi. J. Measurements of 3D flow in a micro-pipe via micro digital holographic particle tracking velocimetry. Meas Sci Technol 2006; 17(7): 1647-51.

[26] Loomans. M. The measurement and simulation of indoor air flow [Ph.D. Thesis]. The Netherlands: Eindhoven University of Technology; 1998.

[27] Mass. H. G, Gruen. A, Papantoniou. D. Particle tracking velocimetry in three-dimensional flows-Part 1: photogrammetric determination of particle coordinates. Exp Fluids 1993; 15(2): $133-46$.

[28] Malik. N. A, Dracos. Th, Papantoniou. D. A. Particle tracking velocimetry in three-dimensional flows-Part 2: particle tracking. Exp Fluids 1993; 15(4-5): 279-94.

[29] Khalighi. B, Lee. Y. H. Particle tracking velocimetry: an automatic image processing algorithm. Appl Optics 1989; 28(20): 4328-32.

[30] Adrian. R.J. Particle-imaging techniques for experimental fluid mechanics. Annu Rev Fluid Mech 1991; 23: 264-304.

[31] Willneff. J, Gruen. A. A new spatio-temporal matching algorithm for 3D-Particle Tracking Velocimetry. In: Proceeding of The 9th International Symposium on Transport Phenomena and Dynamics of Rotating Machinery, Honolulu, USA, Feb 10-14, 2002.

[32] Doh. D. H, Hwang. T. G, Saga. T. 3D-PTV measurements of the wake of a sphere. Meas Sci Technol 2004; 15(6): 1059-66. 
[33] Jones. J.D.C, Andersen. D.J, Greated C.A. Fibre-optic beam delivery systems for particle image velocimetry. Opt Laser Eng 1997; 27(6): 657-74.

[34] Sun.Y, Zhang.Y, Wang.A, Jennifer L. T, James S. B, Besant R.W. Experimental characterization of airflows in aircraft cabins. Part I: Experimental system and measurement procedure. ASHRAE T 2005; 111(2): 45-52.

[35] Sun.Y. Volumetric particle streak-tracking velocimetry and its application in indoor airflow measurements [Ph.D. Thesis]. USA: University of Illinois at Urbana-Champaign; 2007.

[36] Biwole. P. H. Large-scale particle tracking velocimetry for 3-dimensional indoor airflow study [Ph.D. Thesis]. France: Institut National des Sciences Appliquées - Lyon; 2009.

[37] Yan. W. Development of hybrid particle tracking algorithms and their applications in airflow measurement within aircraft cabin mock-up [Ph.D. Thesis]. USA: University of Illinois at Urbana-Champaign; 2010.

[38] Lobutova. E, Resagk. C, Putze. T. Investigation of large-scale circulations in room air flows using three-dimensional particle tracking velocimetry. Build Environ 2010; 45(7): 1653-62. [39] Steinhoff. P, Schmidt. M, Müller. D. Redesign of a 3D PTV system with ANDOR's Neo sCMOS. Germany: Institute for Energy Efficient Buildings and Indoor Climate (EBC), RWTH Aachen University, 2013.

[40] Barker D. Development of A Scalable Real-Time Lagrangian Particle Tracking System For Volumetric Flow Field Characterization [Ph.D. Thesis]. USA: University of Illinois at Urbana-Champaign; 2012.

[41] Melling A. Tracer particles and seeding for particle image velocimetry. Meas Sci and Technol 1997; 8: 1406-16.

[42] Kessler. M, Leith. D. Flow measurement and efficiency modeling of cyclones for particle collection. Aerosol Sci Tech 1991; 15(1): 8-18.

[43] Muller.R.H.G, Rotger.Th, Rotger.Th, Schaumann.O, Markwart.M. Large body aircraft cabin A/C flow measurement by helium bubble tracking. J Flow Visualization 1997; 4(3): 295-306.

[44] Zhao. L, Zhang. Y, Wang. X, Riskowski. G. L, Christianson. L. L. Measurement of airflow patterns in ventilated spaces using particle image velocimetry. In: ASAE/CSAE Annual International Meeting, Toronto, Canada, 1999.

[45] Machacek. M. A quantitative visualization tool for large wind tunnel experiments [Ph.D. 
Thesis]. Switzerland: ETH zürich; 2002.

[46] Ma. B, Ruwet. V, Corieri. P, Theunissen. R, Riethmuller. M, Darquenne. C. CFD simulation and experimental validation of fluid flow and particle transport in a model of alveolated airways. $\mathbf{J}$ Aerosol Sci 2009; 40(5): 403-14.

[47] Bosbach. J, Kuhn. M, Wagner. C. Large-scale particle image velocimetry with helium filled soap bubbles. Exp Fluids 2009; 46(3): 539-47.

[48] Okuno. Y, Fukuda. T, Miwate. Y, Kobayashi. T. Development of three dimensional air flow measuring method using soap bubbles. JSAE Rev 1993; 14(4): 50-5.

[49] Maxey M.R, Riley. J.J. Equation of motion of a small rigid sphere in a nonuniform flow. Phys Fluids $1983 ; 26(4): 883-9$.

[50] Kerho. M.F, Bragg. M.B. Neutrally buoyant bubbles used as flow tracers in air. Exp Fluids 1994; 16(6): 393-400.

[51] Ouellette. N.T, O'Malley. P. J, Gollub. J. P. Transport of finite-sized particles in chaotic flow. Phys Rev Lett 2008; 101(17): 174504 (1-4).

[52] Agüi. J, Jiménez. J. On the performance of particle tracking. J Fluid Mech 1987; 185: 447-68.

[53] Hain. R, Kahler. C. J, Tropea. C. Comparison of CCD, CMOS and intensified cameras. Exp Fluids 2007; 42(3): 403-11.

[54] Ouellette. N. T, Xu. H, Bodenschatz. E. A quantitave study of three-dimensional Largrangian particle tracking algorithms. Exp Fluids 2006; 40(2): 301-13.

[55] Okamoto. K, Nishio. S, Kobayashi. T, Saga. T, Takehara. K. Evaluation of the 3D-PIV Standard Images (PIV-STD Project). J Visual-Japan 2000; 3(2): 115-23.

[56] Zhang. Z. Flexible camera calibration by viewing a plane from unknown orientations. In: Proceedings of the $17^{\text {th }}$ IEEE International Conference on Computer Vision (ICCV'99), Corfu, Greece, Sep 20-27, 1999.

[57] Li D. Numerical and experimental study of volumetric particle tracking velocimetry in a spatial and temporal domain [Ph.D. Thesis]. USA: University of Illinois at Urbana-Champaign; 2008.

[58] Svoboda. T, Martinec. D, Pajdla. T. A convenient multi-camera self-calibration for virtual environments. Presence: Teleop Virt 2005; 14(4): 407-22.

[59] Resagk. C, Lobutova. E, Rank. R, Müller. D, Putze. T, Maas. H-G. Measurement of large-sale 
flow structures in air using a novel 3D particle tracking velocimetry technique. In: 13th International Symposium on Applications of Laser Techniques to Fluid Mechanics, Lisbon, Portugal, June 26-29, 2006.

[60] Doh. D. H, Kim. D. H, Choi. S. H, Hong. S. D, Saga. T, Kobayashi. T. Single-frame (two-field image) 3-D PTV for high speed flows. Exp Fluids 2000; 29(1): 85-98.

[61] Mann. J, Ott. S, Anderson. J. S. Experimental Study of Relative, Turbulent Diffusion, Riso National Laboratory Report, Riso-R-1036(EN), 1999.

[62] Nobach. H, Honkanen. M. Two-dimensional Gaussian regression for sub-pixel displacement estimation in particle image velocimetry or particle postion estimation in particle tracking velocity. Exp Fluids 2005; 38(4): 511-15.

[63] Zhao. L, Zhang. Y, Wang. X, Riskowski, Gerald. L. Analysis of airflow in a full-scale room with non-isothermal jet ventilation using PTV techniques. ASHRAE T 2007; 113(1): 414-25.

[64] Yan. W, Zhang. Y, Sun. Y, Li. D. Experimental and CFD study of unsteady airborne pollutant transport within an aircraft cabin mock-up. Build Environ 2009; 44(1): 34-43.

[65] Barker. D, Lifflander. J, Arya. A, Zhang. Y. A parallel algorithm for 3D particle tracking and Lagrangian trajectory reconstruction. Meas Sci Technol 2012; 23(2): 025301(1-14).

[66] Klimentjew. D, Flick. N. E, Bosselmann. T, Zhang J. 3D hypergraph-oriented air flow analysis based on PTV. In: Proceedings of the 2010 IEEE International Conference on Information and Automation, Harbin, China, June 20-25, 2010.

[67] Klimentjew. D, Flick. N. E, Bosselmann. T, Zhang J. Hypergraph-oriented 3D reconstruction, interpretation and analysis of air flows. Int J Mechatron Autom 2011; 1(1): 9-18.

[68] Cowen. E. A, Monismith. S. G. A hybrid digital particle tracking velocimetry technique. Exp Fluids 1997; 22(3): 199-211.

[69] Kim. H. B, Lee. S. J. Performance improvement of two-frame particle tracking velocimetry using a hybrid adaptive scheme. Meas Sci Technol 2002; 13: 573-82.

[70] Stellmacher. M, Obermayer. K. A new particle tracking algorithm based on deterministic annealing and alternative distance measures. Exp Fluids 2000; 28(6): 506-18.

[71] Li. D, Zhang. Y, Sun. Y, Yan W. A multi-frame particle tracking algorithm robust against input noise. Meas Sci Technol 2008; 19(10): 1054-64.

[72] Kähler. C. J, Scharnowski. Cierpka.C. On the uncertainty of digital PIV and PTV near walls. 
Exp Fluids 2012; 52:1641-56.

[73] Zhang. Y, Sun. Y, Wang. A, Topmiller. J. L, Bennett. J. S. Experimental characterization of airflows in aircraft cabins. Part II: Results and research recommendations. ASHRAE T 2005; 111(2): 53-9.

[74] Wang. A, Zhang. Y, Sun. Y, Wang. X. Experimental study of ventilation effectiveness and air velocity distribution in an aircraft cabin mockup. Build Environ 2008; 43(3): 337-43.

[75] Wang A. Quantifying air distribution, ventilation effectiveness and airborne pollutant in an aircraft cabin mockup [Ph.D. Thesis]. USA: University of Illinois at Urbana-Champaign; 2006. [76] Steinhoff. P, Schmidt. M, Resagk. C, Müller. D. Measurements with a redesigned 3D-PTV system in natural and mixed convection. In: 10th International Symposium on Particle Image Velocimetry, Delft, The Netherlands, July 1-3, 2013.

[77] Lubutova. E, Resagk. C, Tank. R, Müller. D, Putze. T, Maas. H-G. Visualization of large-scale flow structures in air using a novel 3D particle tracking velocimetry technique. In: 12th International Symposium on Flow Visualization, German Aerospace Center (DLR), Gottingen, Germany, Sep. 2006.

[78] Scholzen. F, Moser. A. Three-dimensional particle streak velocimetry for room air flows with automatic stereo-photogrammetric image processing. In: ROOMVENT International Conference, Yokohama, Japan, 1996. p. 555-62.

[79]Sun. Y, Zhang. Y, Zhao. L, Wang X. An algorithm of stereoscopic particle image velocimetry for full-scale room airflow studies. ASHRAE T 2004; 110(1): 75-80.

[80] Müller. D, Müller. B, Renz. U. Three-dimensional particle-streak tracking (PST) velocity measurements of a heat exchanger inlet flow - A new method to measure all three air-flow velocity components in a plane is applied to a steady-state three-dimensional flow. Exp Fluids 2001; 30(6): $645-56$.

[81] Rosenstiel. M, Grigat. R. Segmentation and classification of streaks in a large-scale particle streak tracking system. Flow Meas Instrum 2010; 21(1): 1-7.

[82] Voelker. C, Maempel. S, Kornadt. O. Measuring the human body's microclimate using a thermal manikin. Indoor Air 2014; 24(6): 567-79.

[83] SAI. (2012). Sage Action Inc. Bubble Generator Systems for Air Flow Visualization and Measurement. http://www.sageaction.com/. 
[84] Satake. S, Kanamori. H, Kunugi. T, Sato. K, Ito. T, Yamamoto. K. Parallel computing of a digital hologram and particle searching for microdigital-holographic particle-tracking velocimetry. Appl Optics 2007; 46(4): 538-43.

[85] Satake. S. Study on high speed parallel algorithm using PC grid environment for visualization measurements by Digital Holographic Particle Tracking Velocimetry. Comput Phys Commun 2008; 178(1): 1-7.

[86] Sun. H, Zhao. L, Zhang. Y. Evaluating RNG k- $\varepsilon$ models using PIV data for airflow in animal buildings at different ventilation rates. ASHRAE T 2007; 113(1): 358-65.

[87] Meslem. A, Dia. A, Beghein. C, Hassan. M.E, Nastase. I, Vialle. P.J. A comparison of three turbulence models for the prediction of parallel lobed jets in perforated panel optimization. Build Environ 2011; 46(11): 2203-19.

[88] Sanjuan. C, Suarez. M. J, Blanco. E, Heras. M.d.R. Development and experimental validation of a simulation model for open joint ventilated façades. Energ Buildings 2011; 43(12): 3446-56.

[89] Chami. N, Zoughaib. A. Modeling natural convection in a pitched thermosyphon system in buildings roofs and experimental validation using particle image velocimetry. Energ Buildings 2010; 42(8): 1267-74. 